\title{
Author Correction: Subclonal mutation selection in mouse lymphomagenesis identifies known cancer loci and suggests novel candidates
}

\author{
Philip Webster 1,2,3, Joanna C. Dawes ${ }^{1,2}$, Hamlata Dewchand ${ }^{1,2}$, Katalin Takacs ${ }^{1,2}$, Barbara ladarola1,2, \\ Bruce J. Bolt (1,2, Juan J. Caceres (10 4, Jakub Kaczor 1,2, Gopuraja Dharmalingam,2, Marian Dore ${ }^{1,2}$, \\ Laurence Game1,2, Thomas Adejumo ${ }^{1,2}$, James Elliott1,2, Kikkeri Naresh ${ }^{3}$, Mohammad Karimi1,2, \\ Katerina Rekopoulou ${ }^{1,2}$, Ge Tan ${ }^{1,2}$, Alberto Paccanaro (1) ${ }^{4}$ \& Anthony G. Uren (1) ${ }^{1,2}$
}

Correction to: Nature Communications https://doi.org/10.1038/s41467-018-05069-9; published online 09 July 2018

The original version of this Article contained an error in the hyperlink for the online repository http://mulvdb.org which was incorrectly given as http://mulv.lms.mrc.ac.uk. This has been corrected in both the PDF and HTML versions of the Article.

Published online: 06 March 2019

Open Access This article is licensed under a Creative Commons Attribution 4.0 International License, which permits use, sharing, adaptation, distribution and reproduction in any medium or format, as long as you give appropriate credit to the original author(s) and the source, provide a link to the Creative Commons license, and indicate if changes were made. The images or other third party material in this article are included in the article's Creative Commons license, unless indicated otherwise in a credit line to the material. If material is not included in the article's Creative Commons license and your intended use is not permitted by statutory regulation or exceeds the permitted use, you will need to obtain permission directly from the copyright holder. To view a copy of this license, visit http://creativecommons.org/licenses/by/4.0/.
\end{abstract}

(C) The Author(s) 2019

\footnotetext{
${ }^{1}$ MRC London Institute of Medical Sciences (LMS), Du Cane Road, London W12 ONN, UK. ${ }^{2}$ Institute of Clinical Sciences (ICS), Faculty of Medicine, Imperial College London, Du Cane Road, London W12 ONN, UK. ${ }^{3}$ Imperial College Healthcare NHS Trust, London W12 OHS, UK. ${ }^{4}$ Centre for Systems and Synthetic Biology, Department of Computer Science, Royal Holloway, University of London, TW20 OEX Egham, UK. These authors contributed equally: Philip Webster, Joanna C. Dawes. Correspondence and requests for materials should be addressed to A.G.U. (email: anthonyuren@gmail.com)
} 